\title{
A Comparison of Sampling Methods in Dense Herbaceaous Pasture
}

\section{PAULE S. POISSONET, JACQUES A. POISSONET, MICHEL P. GODRON, AND GILBERT A. LONG}

Highlight: Several methods of vegetation sampling were compared in a very homogeneous herbaceous vegetation: Needle points, double metre points, bayonet points, line transects, area measurements, and harvesting with sorting and weighing. Consistent curvilinear relationships were found between species frequencies, interceptions, and biomasses obtained by several methods. These constant relationships allow the estimation of yields from the double metre points by simple and fast observations. The shape of the curves suggests some ecological relationship between the vegetation attributes analyzed.

Many problems arise in quantitative sampling of dense herbaceous vegetations because of difficulties in delineating individuals or tillers and because of entanglement of species. The main problem is optimalization of time and resources to attain sufficient accuracy. Another question is the kind of relations which exist between estimates obtained by different methods.

Many methods of measuring and surveying vegetation have been reviewed by Brown (1954). They differ by the attributes sampled, sampling techniques, sample numbers, and types of lay-out. Field observations may consist of species lists, frequency (in sub-units), cover (total or by species), density, weight (by species), etc. Sampling methods include areas of various sizes and shapes, lines or belt transects, and points. Point observations have been made by crosswire sighting tube (Winkworth and Goodall, 1962) or with vertical, oblique, or horizontal

The authors are plant ecologists at Centre d'Etudes Phytosociologiques et Ecologiques (CEPE), Centre National de la Recherche Scientifique (CNRS), 34, Montpellier, France.

They acknowledge with thanks the guidance provided by Professor Naphtali Tadmor from the Department of Botany, Hebrew University of Jerusalem, in discussing and editing the paper.

Manuscript received J une 27, 1970. point frame pins (Warren-Wilson, 1959; 1963). Parker (1951) and Long (1958) have used lines and areas for locating sampling units. Methods have been compared by Hédin and Lefebvre (1951), mountier and Radcliffe (1964), and others.

Optimalization of sample numbers with time has been discussed by Hyder et al. (1965) and Fisser and Van Dyne (1966). The distribution of samples may be entirely subjective (i.e. as applied by some phytosociologists), stratified (Gounot, 1960), at random, or regular. Numerous combinations at different levels of these lay-outs have also been used (Boudet and Bayens, 1963).

The present paper evaluates different sampling methods by very detailed observations on dense natural herbaceous pasture in Central France.

\section{The Experimental Area}

The 0.4 hectare, very homogeneous experimental plot is situated on a basaltic plateau, West of Cantal in the Massif Central of France, at $950 \mathrm{~m}$ altitude. The climate is mesothermic with a short summer growing season. Precipitation (rain and snow) totals $1600 \mathrm{~mm}$ annually, and is regularly distributed all around the year. The soil is deep, brown, mull moder humus, very loamy $(45 \%)$ and slightly stony; $\mathrm{pH}$ is 5.5 . The vegetation consists mainly of perennial grasses and forbs. The three dominant species are Festuca rubra, Agrostis vulgaris and Trifolium repens. The area was grazed 6 months a year with a stocking rate of 1-1.5 animal units/ hectare/year. For more details, see Daget and Poissonet (1965).

\section{Experimental Procedure}

Methods Compared.

The following sampling methods were compared:

1) Needle points -Points were defined using a very thin needle, accurately located by a special frame (Long et al., 1972). The number of hits for each species was recorded at each point. This method gives the most accurate point estimates but is time-consuming; it is used as the "reference method" for further comparisons. $8 \times 160$ points were located at $2.5 \mathrm{~cm}$ intervals along $4 \mathrm{~m}$ lines.

2) Double metre points-Points were defined by vertical sighting on the edges of a $2 \mathrm{~m}$ ruler (Daget and Poissonet, 1971). This method is much faster than the previous one: $12 \times 100$ points were recorded at $4 \mathrm{~cm}$ intervals.

3) Bayonet points-Points were defined by the edge of the blade or a "bayonet" (Poissonet et al., 1972), which is convenient in tall herbage. Two hundred eighty-nine points were located randomly, 289 regularly, 256 regularly in 4 subplots of $641 \times 1 \mathrm{~m}$ squares, or $0.5 \times$ $0.5 \mathrm{~m}$ squares.

4) Line transects-Species presence was recorded in $25 \mathrm{~cm}$ segments of 4 lines of $64 \mathrm{~m}$ each.

5) Areas with species ranking-Species presence and their orders (De Vries and De Boer, 1959) were done at regular intervals of (a) "handfuls" (145 units) which were harvested, (b) $0.5 \times 0.5 \mathrm{~m}$ squares (256), (c) $0.25 \mathrm{~m}^{2}$ squares (12), 
(d) $0.25 \mathrm{~m}^{2}$ rectangles (12), (e) $0.25 \mathrm{~m}^{2}$ circles (12).

6) Harvesting of areas with sorting -Forty plots of $1 \times 0.25 \mathrm{~m}$ were harvested, and dry weights were determined after sorting into species categories. Location of plots corresponded to that of the points in methods 1 and 2 .

All methods were tested in the same area within 5 days to reduce variation due to plant growth, and the time spent for each method was recorded (Table 1). Observations were made by four teams of two operators each (one observer + one recorder). Between-team variance was checked by analysis of variance on a latin square design.

\section{Definitions}

Relative frequency of a species is the percentage of sampling units that contain that species. When the sampling unit approaches a point and the number of sampling units is great, relative frequency approaches cover (Godron, 1968). Contribution of frequency is the frequency of a species expressed as percent of the sum of frequencies of all species. As relative frequency approaches cover, contribution of frequency approaches relative cover. Similarly, contribution of interception is the percentage of hits of any one species from the total number of hits of the vegetation; it indicates "relative species volume." A widened meaning of the preceding definition may be applied when the sampling units are lines or arcas; the order (DeVries and DeBoer, 1959) is considered as equivalent to the number of hits. Relative biomass is the dry weight of a species category expressed by percent of the whole herbage. Species rank refers to decreasing relative frequency, contribution of frequency, or contribution of interception and may also be expressed as percentage of the total number of species, either for a single species ( $r$ ) or species category ( $\left.r^{\prime}\right)$. Cumulative values of the other measures are presented in order of decreasing rank.

\section{Results}

When the species relative frequencies

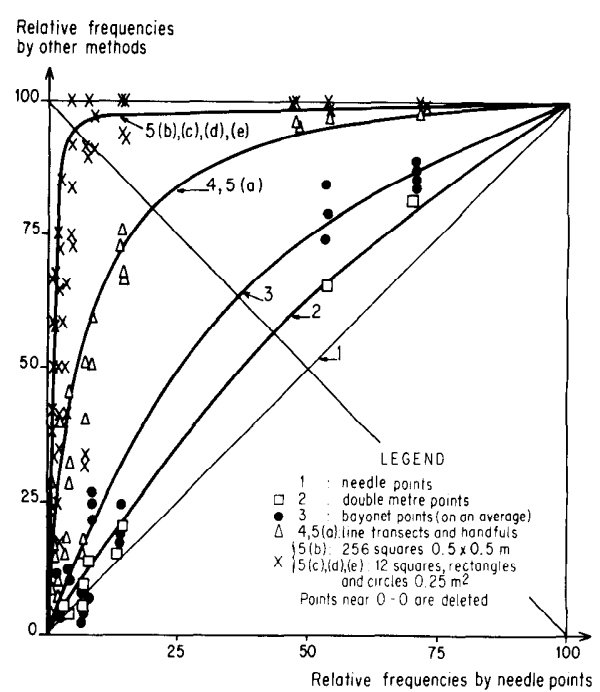

Fig. 1. Relations between relative frequencies as measured by needle points (the "reference method") and other methods.

obtained by the different methods are plotted against those obtained by the most accurate reference method, their values tend to fall on curves of the Lorenz type (Poissonet, 1969) (Fig. 1). The double metre method is closest to the reference method, and the overestimation of relative frequencies increases from it, through bayonet points, line transects, and handfuls to area sampling. A similar family of curves, but with a tendency to underestimation, is obtained when cumulated contributions of frequency or interception from different methods are plotted against those from the reference method. Obviously, the more rigorous point methods give considerably better estimates of species relative frequencies or contributions of frequency and interception than other methods; on the other hand, their success is more observer-dependent.

By all methods, cumulated contributions of frequency are related to cumulated contributions of interception by a concave curve which is a characteristic of each method (Fig. 2), but the under-

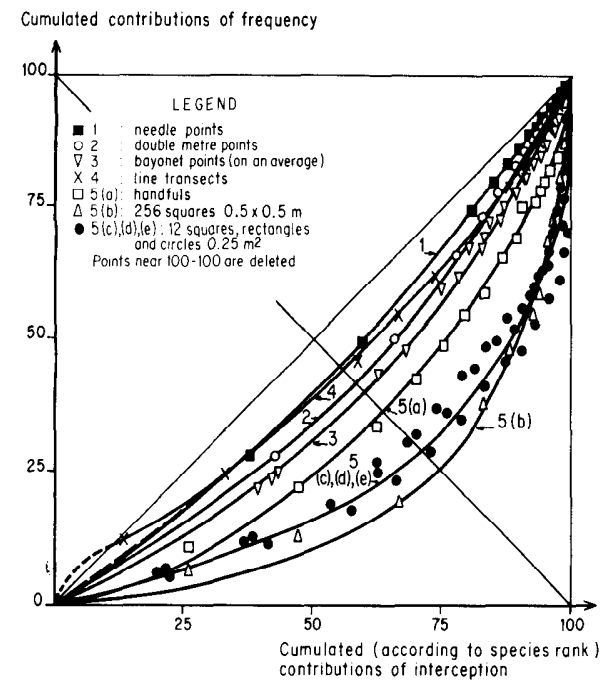

Fig. 2. Relations between cumulated contributions of frequency and interception in various sampling methods.

estimation of the latter by the former is greater with area units than with points. When cumulated contributions of frequency or interception are plotted against species rank (r), most point methods follow the same curve; but line and area methods diverge from it (Fig. 3).

Species relative biomasses show frequently a fairly good linear relationship $(x=y)$ with contributions of interception as measured by point methods, even when cumulated values are plotted (Fig. 4). This enables a direct estimate of relative biomasses from contributions of interception, with an accuracy depending to some extent on the observer. The relationships between relative frequency and contribution of frequency to biomass are less satisfactory.

The relations between relative biomasses and contributions of interception as determined by line transects and area methods are clearly non-linear (Fig. 5). Thus, when only a few "fodder value categories" are considered these methods do not allow a reliable estimation of relative biomasses from interception data.

\section{Discussion}

methods.

\begin{tabular}{lcc}
\hline \hline Sampling units & Sample number & Time \\
\hline 1) Needle points & 1280 & 16 \\
2) Double metre points & 1200 & 18 \\
3) Bayonet points & & \\
(a) at random & 289 & 12 \\
(b) regular & 289 & 16 \\
(c) regular in 4 subplots & 256 & 12 \\
(d) regular in 4 other subplots & 256 & 12 \\
4) Line transects & 1024 & 16 \\
5) (a) Handfuls with harvest & 145 & 16 \\
5) (b) Squares & 256 & 32 \\
5) (c, d, e) Squares, rectangles and circles & 12 & 3 \\
6) Harvest & 40 & 300 \\
\hline
\end{tabular}

These relationships allow fast sampling for yield estimation and species group composition by simple methods; this is their main practical value. The following approach of estimating the distribution of biomasses between categories and species is suggested:

a) Record species frequencies by one of the faster point methods (double metre or bayonet) or by segment or area methods, and calculate contributions of frequency.

b) Calculate contributions of inter- 


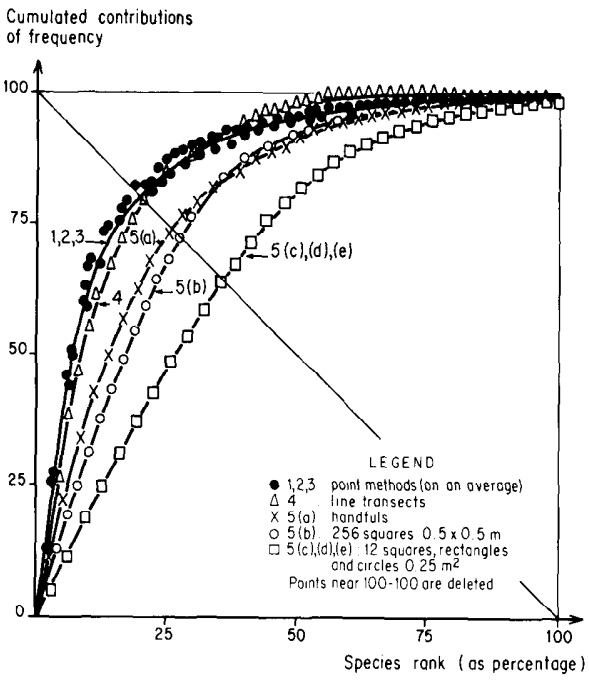

Fig. 3. Relations between cumulated contributions of frequency and species rank expressed as percentage in various sampling methods.

ception from contributions of frequency, using the characteristic curve of the method used (Fig. 2).

c) If a line or area method has been used, calculate the corresponding values for point method from the curves obtained.

d) Sum contributions of interception over species in each category; the sum equals the relative biomass of the category (Fig. 4).

As to the distribution of biomasses between individual species in each category, we may assume that it is proportional to the distribution of contributions of interception (by point methods) in the same way as the distribution between categories. Insofar as this assumption is correct, biomass of each species may be calculated from its contribution of interception and the total biomass.

In this experiment, several types of measurements were carried out on the same very homogenous vegetation at a single site. Care was also taken in the reference method to record hits only by the very sharp tip of a very thin needle. This may explain the clear-cut relationships found between the needle point reference method and other sampling techniques and the lack of such rclationships experienced by other investigators (Mountier and Radcliffe, 1964).

The relationship found between interception, biomass, cover, and rank recorded by different methods may be expressed in a family of 3-dimensional curves. The generality of such curves tends to support the hypothesis of a basic ecological significance of these relationships, at least in the type of vegetation studied. This will be discussed in detail elsewhere.
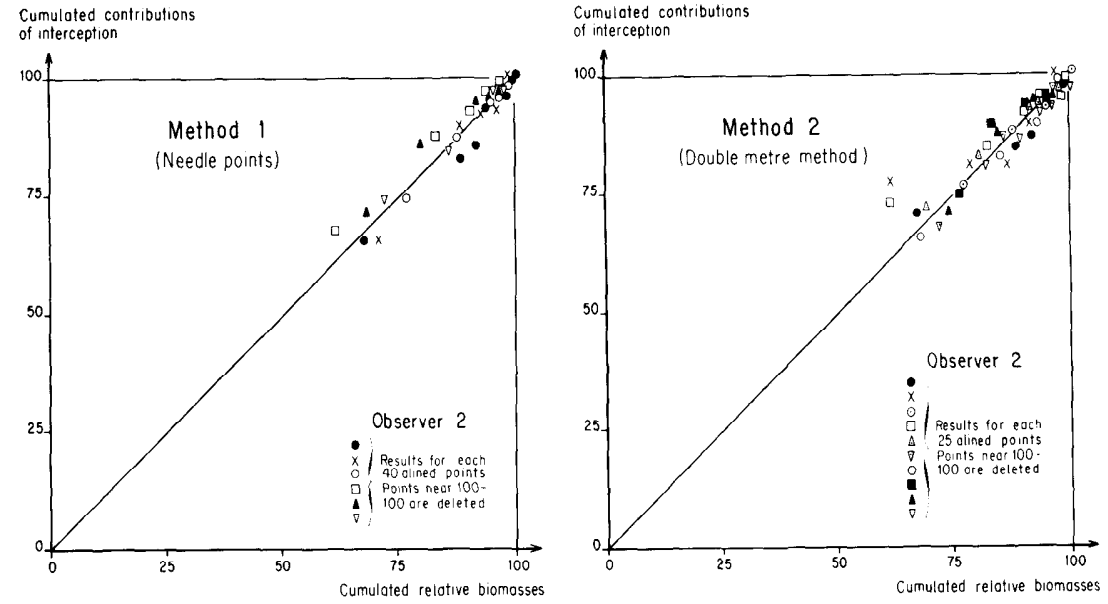

Fig. 4. Relations between relative biomasses and contributions of interception, for species categories, with needle and double metre points.

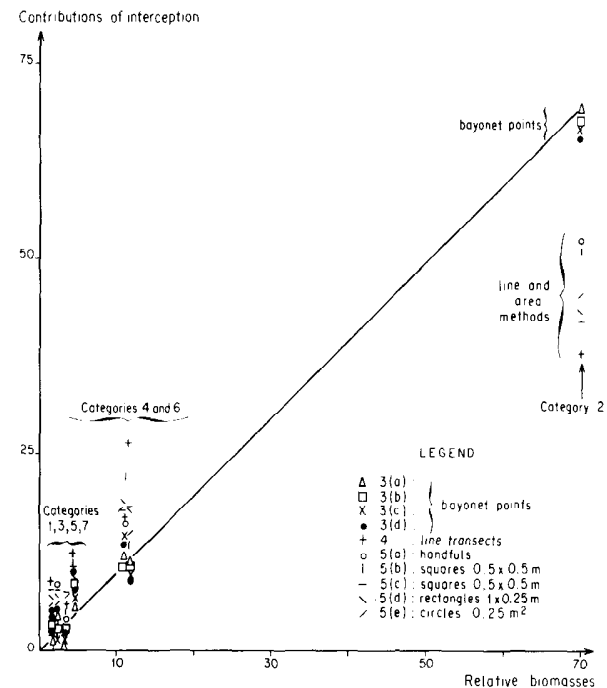

Fig. 5. Relations between relative biomasses and contributions of interception, for species categories, with bayonet points, line and area methods.

\section{Literature Cited}

Boudet, G., and F. Bayens. 1963. Une méthode d'étude et de cartographie des pâturages tropicaux. Revue d'élevage et de médecine vétérinaire des Pays Tropicaux 16, 2:191-219.

Brown, D. 1954. Methods of surveying and measuring vegetation. Comm. Bur. Past. and Field Crops. Bull. 42. Hurley, Berks, England. 233 p.

Daget, Ph., and J. Poissonet. 1965. Contribution à l'étude des herbages des plateaux basaltiques de l'Ouest du Cantal. Série des Etudes locales, $\mathrm{n}^{\mathbf{0}} 16$. C.N.R.S., C.E.P.E., Montpellier, France. 102 p.

Daget, Ph., and J. Poissonet. 1971. Une méthode d'analyse phytologique des prairies. Critères d'application. Ann. Agron. 22, $1: 5-41$.

DeVries, D.M., and Th. DeBoer. 1959. Methods used in botanical grassland research in the Netherland and their application. Herbage Abstr. 24, 1:1-7.

Fisser, H. G., and G. M. Van Dyne. 1966. Influence of number and spacing of points on accuracy and precision of basal cover estimates. J. Range Manage. 19:205-211.

Godron, M. 1968. Quelques applications de la notion de fréquence en écologie végétale. Oecol. Plant. 3:185-212.

Gounot, M. 1960. Méthodes d'étude et d'inventaire de la végétation pastorale et prairiale. Colloque sur l'étude des Prairies. Société Botanique de France. Paris. 95 p.

Hédin, L., and J. M. Lefebvre. 1951. Les méthodes d'analyse botanique dans l'étude agronomique des prairies. Annales de 1'I.N.R.A. série B, 3:376-407.

Hyder, D. N., R. E. Bement, E. E. Remmenga, and C. Terwilliger 1965. Frequency sampling of blue grama range. J. Range Manage. 18:90-94.

Long, G. 1958. Description d'une méthode linéaire pour l'étude de la végétation. Bull. Serv. Carte Phytogéographique, série B, 3:107-127.

Long, G. A., P. S. Poissonet, J. A. Poissonet, Ph. M. Daget, and M. P. Godron. 1972. Improved necdle point frame for exact line transects. J. Range Manage. 25:228.

Mountier, N. S., and J. E. Radcliffe. 1964. Problems in measuring pasture composition in the field. Part. 3 : an evaluation of point analysis, dry weight analy sis and tiller analysis. N.Z.J. Bot. 2:131-142.

Parker, K. W. 1951. A method for measuring trend in range condition on National Forest Ranges. U. S. Dep. Agr., Forest Serv. 26 p. (mimeo.)

Poissonet, P. S., Ph. M. Daget, J. A. Poissonet, and G. A. Long. 1972. Rapid point survey by bayonet blade. J. Range Manage. 25:313.

Poissonet, P., and J. Poissonet. 1969. Etude comparée des diverses méthodes d'analyse de la végétation des formations herbacées denses et permanentes. Conséquences pour les applications agronomiques. Document $\mathrm{n}^{\mathrm{O}}$ 50, C.N.R.S., C.E.P.E., Montpellier, France, $120 \mathrm{p}$.

Warren-Wilson, J. 1959. Analysis of the spatial distribution of foliage by two dimensional point quadrats. The New Phytologist 58:92-101.

Warren-Wilson, J. 1963. Estimation of foliage denseness and foliage angle by inclined point quadrats. Australian J. Bot. 11:95-105.

Winkworth, R. E., and D. W. Goodall. 1962. A crosswire sighting tube for point quadrat analy sis. Ecology 43:342-343. 